\title{
Sans soleil, o trabalho do imaginário ${ }^{1}$
}

/////////////////// Barbara Lemaître

1. Texto original: LEMAÎTRE, B. "Sans soleil, le travail de l'imaginaire”. In: DUBOIS, Philippe (Org.). Théorème 6. Paris: Sorbonne Nouvelle, 2002. Tradução de Krishna Gomes Tavares.

2. Professora da Université Sorbonne Nouvelle - Paris III e pesquisadora do Institut de Recherche sur le Cinéma et l'Audiovisuel. Publicou, entre outros, Entre film et photographie. Essai sur l'empreinte (Presses Universitaires de Vincennes, 2004). 


\section{Resumo}

Sans soleil se apresenta, inicialmente, como um conjunto de imagens heterogêneas. No entanto, uma questão é trabalhada no filme do início ao fim: a noção de imaginário compreendida no sentido psicanalítico de trabalho ou de experiência. O imaginário em Sans soleil é ao mesmo tempo um espaço em que o indivíduo pode tornar-se interlocutor, um instrumento de conexão entre zonas heterogêneas e um movimento que unifica os contornos da experiência da alteridade.

\section{Palavras-chave}

Sans soleil, imaginário, psicanálise

\section{Résumé}

Sans soleil se présente d'abbord comme un ensemble d'images hétérogènes. Pourtant, une question est présent dans le film du début au jusqu'à la fin: la notion d'imaginaire, à entendre en son sens psychanalytique du travail ou de l'expérience. L'imaginaire dans Sans soleil est done à la fois un espace où l'individu peut se pendre comme interlocuteur, un instrument de raccordement entre des zones hétérogènes et un mouvement qui épouse les contours de l'expérience de l'altérité.

\section{Mots-clés}

Sans soleil, imaginaire, psychanalyse 
A origem deste texto está em uma questão simples, que reaparece a cada nova exibição de Sans soleil: do que nos fala Marker? Se o "tema" de seus outros filmes pode ser sintetizado e nomeado, mesmo que de modo reduzido, é difícil situar Sans soleil em uma questão precisa. $\mathrm{O}$ que podem ter em comum uma dama de honra da corte imperial do Japão do século XI, guerrilheiros africanos em luta contra a colonização portuguesa, homens e mulheres de Tóquio apegados a signos e lendas que se desdobram em seu entorno (tudo isso nos é transmitido pelo intermédio de um viajante, que navega, essencialmente, entre a Guiné-Bissau e o Japão)? Sans soleil se apresenta, inicialmente, como um conjunto de imagens heterogêneas. Parece-me aleatório extrair desse filme um único tema e, desse modo, esperar dar conta de sua especificidade. No entanto, me parece que uma questão é trabalhada no filme do início ao fim. Uma questão que não é de fato um tema e que vai além do filme e até mesmo do cinema. Essa questão roda em torno de uma noção de imaginário compreendida no sentido psicanalítico de trabalho ou de experiência.

Inicialmente, eu gostaria de definir essa noção da forma mais clara possível. O imaginário tem na psicanálise uma significação

3. LACAN, J. "Le stade du miroir comme fondateur de la fonction du Je, telle qu'elle nous est révélée, dans l'expérience psychanalytique". In: LACAN, J. Écrits I. Paris: Seuil, 1966. muito complexa e frequentemente indissociável da cura psicanalítica: não é uma noção muito cômoda de manusear fora do contexto terapêutico. A definição mais frequentemente citada é a elaborada por Jacques Lacan em seu célebre texto sobre o estádio do espelho 3 ("le stade du miroir"). Lacan se interessa pela constituição do imaginário como uma das etapas da evolução 
psíquica do ser humano; essa etapa remete ao momento no qual, ao perceber seu reflexo em um espelho, a criança se reconhece e se identifica com essa imagem. Desse modo, Lacan “atribui à imagem um papel constitutivo no que nós podemos continuar a chamar de Eu" (CHEMANA, 1993, p. 292).

De um modo geral, o imaginário remete a um conjunto de imagens fundadoras da relação de um indivíduo, não somente com ele mesmo mas também com o outro e com o seu meio. Eu mesmo, o outro, o mundo, tudo isso existe somente através do que eu projeto; eis o imaginário. Ele é descrito como sendo, por excelência, o campo da ilusão, o que explica que ele seja frequentemente assimilado à ficção e à invenção. Todavia, mesmo que o imaginário participe da construção de uma ilusão, ele tem um papel essencial, simplesmente porque ele está sempre presente, como um filtro que se intercala entre nós e o mundo. A psicanálise de Jacques Lacan (1966), assim como a filosofia de Mikel Dufrenne (1976), por exemplo, insistiram sobre esse ponto: o imaginário não pode ser localizado fora do real.

O que ocorre a partir do momento em que o imaginário não diz respeito exclusivamente a imagens com características particulares, como aquelas com as quais a psicanálise se preocupa, a saber, as imagens psíquicas? Ao falar delas, eu retomo fielmente o vocabulário psicanalítico, que as nomeia de imagens mentais. De acordo com Edgar Morin (1956, p. 210), em O cinema ou o homem imaginário, "o cinema reflete o comércio mental do homem com o mundo".

Um comércio mental com o mundo; eis o que me parece que Chris Marker realiza em Sans soleil. Seja o que for essa estranha história de homens captados nas imagens, o filme de Marker se desdobra e explora alguns aspectos importantes, tais como: Para que serve a imagem? O que é o imaginário? Que funções certas imagens preenchem na apreensão do mundo pelo homem? Certamente, essas questões atravessam todo o cinema. Mas poucos filmes as enfrentam tão diretamente quanto Sans soleil.

Dito de outro modo, de certa forma, um grande número de filmes - talvez todos os filmes - repousam fundamentalmente 
sobre tais interrogações, mas poucos as reconhecem a ponto de transformá-las no objeto principal de uma reflexão. Sans soleil possibilita observar a emergência progressiva de uma relação, através da confrontação de um indivíduo com um conjunto de imagens, que o coloca ora como produtor, ora como espectador. O filme decompõe e encarna um processo psíquico - que é um trabalho de imagens - através do qual nós apreendemos tudo o que está em nossa volta.

Ressalto que tal problema contém uma importante questão para a teoria da imagem: remeter a imagem fílmica ao imaginário que a elabora e que ela põe em cena nos leva a uma interrogação sobre os vínculos entre imagens perceptíveis (ou imagens-objetos, segundo a expressão de Serge Tisseron, 1995) e imagens mentais, e a estabelecer entre elas uma ponte. Julgaremos, talvez, perigoso, ou até mesmo abusivo, empregar o termo imagem para qualificar fenômenos de qualidades, ou melhor, de texturas fortemente diferentes. No entanto, acredito que o que separa a imagem mental da imagem do filme não deve nos impedir de ressaltar o que elas têm em comum. E tentarei mostrar que o que permite essa aproximação encontra-se em um determinado modo de funcionamento das imagens.

Concretamente, como tudo isso aparece no filme? Um viajante ocidental efetua idas e vindas entre o continente africano e o asiático. Ele será colocado na presença de um conjunto de realidades que lhe são radicalmente estrangeiras; pode-se dizer que isso é uma experiência de alteridade, uma confrontação com o outro. Essas realidades são de ordem social, política, cultural, geográfica, histórica... De qualquer forma, esse viajante curioso vai tentar compreender essas realidades que, inicialmente, lhe escapam. Como o estrangeiro, exterior a essas realidades, pode apreendê-las? Porque ele é um cameraman, ele será conduzido a passar pela imagem. Mas ele também é escritor. Tendo acumulado numerosas imagens do Japão, da Guiné-Bissau ou de outros lugares, o viajante de Sans soleil volta a essas imagens e se interroga sobre suas funções, sobre o que elas lhe possibilitam 
apreender do outro e sobre o que permanece na imagem dessas realidades captadas. Pela criação de um dispositivo singular e pela modificação constante da relação do viajante com essas imagens, o filme nos permite ver a maneira segundo a qual um indivíduo domina esse conjunto de realidades das quais ele está excluído. Certamente, o sujeito não é aquela criança da teoria lacaniana; mas, passada a fase do espelho, o imaginário continua seu trabalho entre o homem e seu mundo (AUMONT, 1990, p. 88).

\section{O espaço do imaginário ou a invenção de um outro Eu}

Sans soleil consiste, aparentemente, na mise-en-scène das cartas enviadas por um escritor-cameraman chamado Sandor Krasna. O nome de Krasna evoca Michel Krasna, autor presumido da banda eletroacústica do filme, e Norma Krasna, roteirista de Hitchcock em Mr. and mrs. Smith ${ }^{4}$. Sandor Krasna pode não existir realmente,

4. É notório que Marker frequentemente faz referência à Hitchcock. Sans soleil e La jetée se constituíram, notadamente, a partir de alusões a Vertigo. mas o filme lhe atribui um lugar central no dispositivo enunciativo: deveríamos lhe remeter o conjunto das reflexões e das imagens que o narrador nos restitui. O narrador é, na verdade, uma narradora. Eu voltarei a esse ponto mais tarde. Nos créditos, Marker atribui a si mesmo apenas a função da montagem e a da composição do conjunto; ele é, por assim dizer, o organizador. Aquele que volta a um material constituído anteriormente com o objetivo de voltar à imagem, definindo, assim, uma postura que encontraremos em outras iniciativas do cineasta, como em Si j'avais quatre dromadaires.

A maioria dos olhares lançados sobre o filme reconhece imediatamente Marker atrás de Sandor Krasna, sobrepondo, uma à outra a pessoa que escrevia e aquela que havia composto o filme. Guy Gauthier (1990) assim exclama: "Naturalmente, é Marker que escreve para ele mesmo". Isso não nos impede de questionar esse "desdobramento" do cineasta. Por que criar um personagem responsável pela escrita das cartas e pelas tomadas? Podemos esclarecer esse desdobramento ao pegarmos um pequeno atalho pelo Le dépays, o livro que Marker elabora ao mesmo tempo que Sans soleil. 
5. Nota dos editores: trata a si mesmo por $t u$, pronome que na língua francesa indica proximidade com o interlocutor.
No livro, Marker se recusa a dizer "eu”, mesmo que o texto seja essencialmente um monólogo: ele se tuteia ${ }^{5}$ no decorrer do livro. O "tu" é colocado também como um outro, mas Marker fornece as indicações necessárias para sua identificação. Ele escreve: "Não é somente a leitura assídua de Jorge Semprún que me fez empregar, desde o início do texto, o tuteio romanesco. Sobretudo, a vontade instintiva de estabelecer uma distância entre aquele que, de setembro de 1979 a janeiro de 1981, fez estas fotos no Japão e aquele que em 1982 escreve em Paris. Não é o mesmo. Não somente por questões claramente biográficas: as pessoas mudam, nunca se é o mesmo, é preciso se chamar de "tu" toda a sua vida. Mas eu sei que, se eu voltar amanhã ao Japão, eu encontrarei o outro, eu serei o outro" (MARKER, 1982).

O outro, explicitamente instituído por Marker em Le dépays, não reivindicado em Sans soleil, é, portanto, como uma parte dele mesmo colocado a distância, um "eu” escondido sobre um "tu" ou sobre um "ele". A experiência da viagem, no decorrer da qual o indivíduo é confrontado com um mundo não familiar, o modifica e o constitui como um outro ordinário. Esse outro não desaparece completamente com o retorno, quando o viajante reintegra o seu meio, mas permanece ligado a esse além onde ele apareceu. É um outro "ele", deixado em terra estrangeira, que Marker situa no coração da enunciação de Sans soleil. Rosalind Krauss (1990, p. 84) observa que "o habitante do imaginário não tem identidade unívoca ou orientada em torno de um ponto focal único, pois sua identidade é simultaneamente constituída dele mesmo e de um outro".

Segundo o psicanalista Pierre Kaufmann, a invenção de outro "eu" é uma das determinações do espaço imaginário. O indivíduo coloca a distância essa pequena voz - sua "consciência" - e, tendo sido criada a distância, ele pode se assumir como interlocutor. Kaufmann ([s.d], p. 738) acrescenta: “A constituição do mundo imaginário, sua coesão, sua organização em uma totalidade original, tem seu fundamento na singularidade do destinatário, para o qual a mensagem subjacente se endereça. Não teria cada indivíduo, na sua intimidade, um interlocutor 
secreto com o qual seu discurso se reúne e encontra sua norma e sua medida?". O discurso se unifica. Dito de outra forma, ele está disperso... O espaço da imaginação nasce justamente nessa lacuna, no intervalo entre o indivíduo e o outro que ele inventa para si mesmo. A partir disso, pode-se considerar que Marker e Krasna estão cada um em um polo desse espaço.

Há um problema. A citação de Kaufmann mostra que esse outro, esse duplo, é ao mesmo tempo aquele que fala e aquele para quem a palavra é destinada. Ora, o destinatário é um problema em Sans soleil. As cartas são lidas por uma mulher, a quem elas parecem se endereçar. Essa mulher é uma atriz; no entanto, ela não interpreta o texto, ela não acelera o ritmo; ao contrário, ela transmite em um tom quase que neutro, uma voz branca. Eu tenderia a vê-la, sobretudo, mais como uma mediadora que como uma destinatária, e considerar o filme inteiro como a resposta de Marker àquele que lhe escreve do fim do mundo. Essa presença feminina em Sans soleil pode estar relacionada a outra presença feminina, que aparece em um dos últimos filmes de Marker, Level 5.

Nesse filme, uma mulher chamada Laura se dirige, de frente para a câmera, a um homem dado como morto. Localiza-se uma variante complicadora da relação triangular. Em Sans soleil, o triângulo que compõe o filme se organiza a partir de Krasna, da narradora e de Marker. Em Level 5, trata-se de um homem morto, de um amigo cineasta (Marker) e dessa mulher onipresente. Mais uma vez é muito tentador, mas também muito problemático, colocar o cineasta como o criador do jogo e ver nesse homem morto o seu duplo fantasmagórico. Level 5 aparece, portanto, como uma palavra vinda, pelo menos em parte, de entre os mortos... O que me parece interessante é que a figura feminina se oferece, nos dois filmes, como uma figura intermediária entre duas masculinas. Se a mulher, em Sans soleil, assim com em Level 5, não é a destinatária, ela é uma mediadora indispensável para a emergência e para a transmissão da palavra.

O espaço do imaginário em Sans soleil consiste, sobretudo, na invenção pelo cineasta de um outro "ele mesmo": o outro que permaneceu no Japão, ou na África, ou em outro lugar; e, 
no espaço traçado por esse desdobramento, um segundo outro surge, o outro feminino. A primeira aparição do imaginário se atém, essencialmente, a um desdobramento singular, que permite ao indivíduo se colocar como interlocutor. Esse conjunto de observações aborda o filme em sua globalidade. É preciso, nesse momento, se ater mais precisamente ao filme.

\section{A montagem da memória ou o imaginário da montagem}

Sans soleil está estruturado em quatro atos, precedidos por um prólogo. Ao escrever essa frase, me dou conta de que me pautei na decupagem do filme tal qual ele aparece no comentário escrito. Se nós lhe assistimos sem ter esse texto em vista, nenhuma das suas partes pode ser chamada de ato, e a separação entre as diferentes partes não são tão evidentes; eu me refiro por comodidade à decupagem, pois ela nos oferece um instrumento muito útil de orientação no filme.

Cada parte entrelaça imagens diversas, no estágio de idas e voltas conduzidas por Marker, segundo uma lógica singular. Não se trata de uma alternância estrita, regular, entre dois polos geográficos. $\mathrm{O}$ ato "dois" se desenvolve quase inteiramente no Japão - em alguns momentos, no Japão contemporâneo ao filme e, em outros, no Japão dos anos 60. O ato "três" inicia-se na Guiné-Bissau, confronta as imagens da guerrilha àquelas da pós-revolução e segue para São Francisco, desde Vertigo até Sans soleil, e para Okinawa, em 1945. Inicialmente, o filme aparece como uma tentativa de recolher os fragmentos espalhados de um quebra-cabeça incompleto. O terceiro ato oferece um índice para compreender a lógica que preside essas junções de um lugar a outro, de uma época a outra. De fato, é nesse momento que Marker formula a ideia de montagem da memória.

Antes de descrever esse raccord peculiar, é preciso dizer que não se encontram vestígios desse procedimento nas teorias clássicas da montagem e que, se Marker não é seu inventor, é ao menos um fervoroso utilizador dela. Esse "raccord de lembrança” permite atravessar a lacuna entre dois motivos, duas imagens, dois tempos, dois espaços, dois pontos de vista ou ainda dois acontecimentos, 
em princípio distantes ou desconectados radicalmente. Ela pode ser induzida por um comentário ou por um parentesco visual, e ela é mais ou menos explícita. Assim, qualquer coisa em um rosto japonês, um olhar particular, pode evocar, chamar ou lembrar um outro olhar mostrado em um rosto africano. A compreensão desse raccord - do que apesar de tudo faz a montagem - leva a uma confrontação com o imaginário daquele que a produziu. De fato, somente a passagem através de uma rede de imagens intermediárias, ora invisíveis ou atualizadas (é preciso então considerar a montagem entre os planos não consecutivos), ora virtuais e sugeridas (aqui, é necessário imaginar ou restabelecer o que está ausente entre os planos), permite compreender o vínculo entre os dados visuais e os sonoros comparativamente. O "raccord de lembrança" descobre o imaginário, não apenas como possibilidade para o indivíduo se colocar como interlocutor mas também como instrumento de ligação entre elementos heterogêneos.

Passaremos, por exemplo, de um plano sobre as bonecas japonesas a um plano que nos permite ver uma boneca africana, ou melhor, uma boneca com a qual brincam pequenas africanas. A boneca japonesa é uma minijaponesa; no entanto, a boneca da Guiné possui um pequeno rosto muito branco... e nada africano. De certo modo, nada mais distante que uma boneca do que outra boneca: elas não têm a mesma aparência nem exatamente a mesma função, pois elas não assumem a mesma experiência (as bonecas também têm uma historicidade). A montagem da memória possui, nesse caso, uma eficácia crítica, e o salto entre esses dois planos mostra bem o que a colonização produz, especialmente no nível do imaginário: a pequena africana não tem uma boneca à sua imagem, com a qual possa se identificar.

Encontramos outro "raccord de lembrança" interessante no início do filme. No momento em que a câmera para sobre a imagem de uma jovem africana, o comentário coloca a seguinte questão: "Como se lembrar da sede?" As imagens que vêm a seguir propõem uma resposta: pela evocação de um dia no qual alguns japoneses, entre os mais pobres, são vistos oferecendo saquê em um bistrô de Namidabashi — saquê oferecido, em outras circunstâncias, sobre as 
tumbas dos mortos... Na passagem, a memória está incrustada em um único corpo: não há memória coletiva; somente "mil memórias de homens". Isso o filme nos ensinará, um pouco mais adiante, um pouco mais tarde (sem dúvida, é preciso rever a ilusão de uma memória coletiva e a ilusão de um imaginário coletivo).

Esse raccord se inscreve entre duas paradas sobre a imagem (e sobre um rosto): o rosto da jovem africana e o de um velho japonês, que se fazem ecoar. A montagem não reproduz uma imagem (e uma outra imagem lhe sucede diretamente), mas circula entre várias, no intervalo circunscrito a dois planos "suspensos". Água, sede, saquê, embriaguez, leite fermentado e mais saquê: eis uma junção que opera na duração, pelo intermédio de uma rede que associa livremente as palavras e os motivos ordenados em torno do extremo da sede. Ao raccord clássico que reduz ou elimina a distância entre dois planos - pela semelhança de um momento, pela lógica de um olhar - , Marker opõe o intervalo, ou seja, uma construção que leva em conta a distância, reconhecendo-a e enfatizando-a. A sede, por duas vezes, mas não a mesma sede.

Outro gesto crítico é dirigido a toda forma de montagem ocultante, que apaga ou nega o intervalo. Quando Marker escreve que ele não está à procura de contrastes, podemos ver não a negação entre situações regularmente opostas, mas o desejo de mensurar a distância que as separa. Daí o intervalo. Em um primeiro momento, constatamos que essa montagem tem como função colocar em relação fragmentos do filme que mantêm ligações pouco aparentes para o espectador. É preciso acrescentar que a montagem não atua somente entre sequências ou imagens sucessivas: ela intervém, às vezes, no interior de uma imagem ou de uma sequência e conduz, pelo intermédio do texto, uma imagem visível a uma invisível. Encontraremos, então, na imobilidade de homens adormecidos em um barco, o tempo de uma travessia, a mesma suspensão temporal em um momento de alerta a bombas de uma guerra passada.

Mais especificamente, saberemos que certo bar de Shinjuku tem a faculdade preciosa de fazer ressurgir, apenas para alguns ouvintes, algumas notas da música do filme La jetée... Por que essa montagem da memória entre o bar de Shinjuku e La jetée? 
A resposta se encontra no Tokio Ga, de Wim Wenders... em que constatamos que o imaginário, assim como afirma Mikel Dufrenne (1976, p. 103), não retorna a uma “arquitetura-transcedental”!

O "raccord de lembrança" coloca em contato zonas ordinariamente separadas por uma divisão estanque: aqui e além, agora e depois, o outro e eu. Mas esse raccord, daí a sua originalidade, não procura preencher a distância entre essas zonas nem atenuá-la. A montagem a torna visível e a exibe. Entretanto, esse raccord não é da mesma ordem do que se costumou chamar de falso raccord: não enfatiza tanto a artificialidade e a restrição do contínuo sobre o descontínuo, mas aproxima, apesar de tudo, ordens e coisas dessemelhantes. Ela não é um fator de destruição da continuidade, mas um instrumento criador de outra continuidade, mais ou menos secreta, fundada sobre indivisíveis ligações. A montagem da memória rompe a imagem e a coloca em uma dimensão suplementar que não está somente na própria imagem mas que assegura sobretudo a relação que essa imagem institui com alguém que a vê. Seja qual for o valor poético, a montagem é, em seu princípio, um gesto transgressivo com o objetivo de conciliar o inconciliável, reparar o distanciamento - e não apenas entre os tempos: aqui e além, agora e depois, o outro e eu. A montagem da memória, fundada sobre o imaginário, é uma montagem crítica.

Essa força de expansão sobre a qual se funda a montagem das lembranças, o movimento pelo qual cada imagem atrai uma ou muitas outras - que, imediatamente, tornam-se visíveis ou não —; é tudo isso que o termo imaginário procura identificar. $\mathrm{O}$ imaginário é, no sentido matemático, o expoente de toda imagem.

Uma vez aceita a ideia de que a maioria dos diferentes elementos que compõem o filme mantém tais vínculos, ainda não compreendemos qual é a trajetória que se efetua da primeira imagem até a última. É preciso dar conta de uma reflexão que percorre esse e muitos outros filmes do mesmo cineasta. Essa reflexão refere-se à imagem e, sobretudo, a seus poderes ou a suas funções.

Sans soleil resulta da tensão entre, de um lado, uma imagem isolada (uma imagem-movimento, um plano islandês 
precisamente) e, de outro, um conjunto de imagens do Japão, da Guiné-Bassau, a respeito das quais o viajante se interroga. Dois problemas emergem conjuntamente: inicialmente, será preciso introduzir a única imagem em uma formação, encontrar para ela um lugar entre as outras. Em seguida, será preciso compreender o conjunto, extremamente resistente, formado por todas as outras imagens. Os dois problemas estão ligados, pois somente após ter percorrido e questionado as imagens dessas realidades estrangeiras o viajante será capaz de localizar sua imagem. Em que momento e em que lugar, solicita o viajante, associar minha imagem de felicidade às outras imagens? O que fazer com essas imagens que são imagens do outro? Como situar-se em relação a elas, como apreendê-las, como compreendê-las?

\section{A experiência da alteridade: os poderes da imagem, a atividade do imaginário}

A citação inaugural de Racine nos leva a considerar o filme como uma tragédia. Essa propensão ao trágico é também atribuída pelo título do filme, e a sequência de abertura situa os dados. A tragédia é, a princípio, a de uma imagem de felicidade...

A felicidade para Marker seria, inicialmente, o horizonte de livros de Giraudoux. Ele fala a respeito dos últimos romances: "A que rumo tendem esses romances aparentemente desprovidos de sentido e adequados ao real? Rumo a uma imagem de felicidade humana" (MARKER, 1952, p. 18). Em seguida, a ideia de felicidade se encarnou em algumas imagens de La jetée, imagens surgidas como confissões... Enfim, a felicidade se associa à descoberta do filme de mesmo título e ao encontro decisivo com seu realizador, Alexandre Medvedkine. O filme de Medvedkine, realizado em 1934, começa com um velho homem que morre por alguns bolos. A felicidade - nenhum dos personagens do filme a conhece - é dada como uma coisa indispensável que é preciso procurar, uma coisa preciosa que deveria, ao menos, como uma mercadoria qualquer, encher um saco. 
A seu modo, a abordagem de Sans soleil responde ao filme de Medvedkine. A questão não é mais “o que é a felicidade?” ou "será que ela está em um pequeno saco?", mas "onde achar um lugar para uma imagem de felicidade?”; é o que o comentário expressa: "A primeira imagem da qual ele me falou foi a de três crianças em uma estrada, na Islândia, em 1965. Ele me dizia que, para ele, essa era a imagem de felicidade e que ele havia tentado, vária vezes, associá-la a outras imagens - no entanto, isso nunca funcionou" (MARKER, 1993, p. 79). A imagem em questão representa crianças andando ao longo de uma falésia, conscientes de estarem sendo filmadas; elas se distanciam lentamente, até ficarem fora da vista. A felicidade é, sem dúvida, a imagem frágil de um instante que anuncia a proximidade de seu desaparecimento.

Essa imagem e o comentário nos colocam um pouco antes do fim da terceira parte: "Na Islândia, eu coloquei a primeira pedra de um filme imaginário. Neste verão, eu havia encontrado três crianças em uma estrada..." Nós sabemos, agora, que o germe do filme se encontra nessa imagem, que ela continha alguma coisa que iria desencadear a realização da obra. Por que essa imagem é tão única, por que ela não pode ser associada a nenhuma outra imagem? Primeira resposta: porque é preciso deixar o tempo fazer o seu trabalho sobre ela.

O trabalho do tempo sobre a imagem consiste em liberá-la da mentira, ou seja, liberá-la de seu referencial na realidade; a mentira é a imagem tida como reflexo de alguma coisa situada na realidade - pois, se a imagem permanece vinculada à realidade, ela passa e se esvai. A imagem deve, portanto, romper as amarras com o seu referencial. O plano é finalmente inserido após as cerimônias ritualísticas do Dondo-Yaki, ou seja, após as celebrações japonesas da destruição, do abandono, do desparecimento. A imagem encontra um lugar; no entanto, não é mais a mesma imagem. Num primeiro momento, ela tornou-se estremecida - "mas por que as imagens começam de repente a estremecer?". O plano recupera algumas imagens que o filme, no início, havia censurado, "para deixar limpo". Essa imagem se encontra dotada de uma sequência, de um destino; ela é colocada 
em perspectiva: ela adquiriu subitamente um futuro, dado por Haroun Tazieff, que filmou o mesmo lugar cinco anos depois de Marker; mas esse futuro dado à imagem é também um fim, pois uma erupção vulcânica arrasou a paisagem. Desse modo, a imagem de felicidade somente encontra seu lugar no momento no qual o que vemos não existe mais a sua volta. Somente quando todas as referências da realidade são apagadas definitivamente a imagem pode enfim encontrar um lugar, um status particular. Nesse sentido, a imagem é como os objetos da cerimônia do Dondo-Yaki, "um resíduo que tem direito a imortalidade"...

Nesse divórcio entre a imagem e seu referencial, Hayao Yamaneko é uma figura interessante. Ele começa desfigurando a imagem fílmica em seu sintetizador e faz surgir, desse modo, no lugar da imagem anterior um "pequeno bloco de realidade", uma não imagem. A não imagem (eletrônica) é a imagem do que não pode ser nomeado na realidade e que, portanto, existe: imagem daquilo que não tem nome nem existência oficial, mas, de qualquer forma, tem uma existência, imagem clandestina... As intervenções sucessivas de Hayao, a partir do segundo ato, elaboram, finalmente, uma imagem paradoxal: uma imagem que não se remete mais a um referencial nomeável, mas encarna ou indica um visível sem nome. O gesto de Hayao Yamaneko, comparado ao de Kurosawa no início de Kagemusha, tem por objetivo colocar em evidência essa parte invisível, porém essencial, da relação entre imagem e seu referencial: o imaginário.

Disso decorrem algumas preposições fundadoras de uma postura singular frente à imagem: distanciar o máximo possível o referencial, tentar não fechar a imagem em ligações espaçotemporais muito coordenadas e olhar essa imagem de outro modo, como se fosse o fóssil de um acontecimento ou de um objeto da realidade. De seu modo, o filme unifica a questão que Georges Didi-Huberman (1992) não cessou de reformular: o visual começa no ponto em que, frente à imagem, todas as tentativas de nomeação, todas as nossas certezas descritivas desaparecem. Essa imagem de felicidade que pode associar-se somente às imagens que celebram o desaparecimento - a felicidade na imagem 
como característica de uma perda - dá ao filme uma tonalidade levemente melancólica. Sans soleil é quase que inteiramente uma lista de imagens perturbadoras; o filme tece uma carta avassaladora da infelicidade humana. Guerra, morte, pobreza, exílio, suicídio, esperança revolucionária frustrada, impossibilidade de conjugar a memória e a história; compreendemos que seria preciso um filme inteiro para situar a imagem da felicidade!

Mas isso não é tudo. Assim que o viajante consegue, finalmente, inserir sua imagem de felicidade, ele completa uma jornada e percorre, em todos os sentidos, a geografia da infelicidade. Essa jornada, essa confrontação com as imagens do outro, se traduz em uma modificação progressiva de sua relação com as imagens. Por não poder ressaltar tudo o que o filme diz ou mostra dessa relação, eu escolhi alguns instantes que me parecem constituir tantas etapas. Etapas referentes a quê? Ao que é preciso lembrar a respeito da definição de imaginário, formulada no início do texto, como "um conjunto de imagens constitutivas de um sujeito no mundo". O filme Sans soleil permite reconhecer o movimento pelo qual um indivíduo consegue finalmente apreender o outro através de suas imagens. O filme inteiro esforça-se para construir a relação entre um indivíduo colocado como observador e esses nós de realidades singulares que definem o outro. O trabalho do filme é o trabalho do imaginário.

A primeira interrogação essencial sobre a imagem diz respeito ao que o filme apresenta como a igualdade do olhar. Essa igualdade consiste, inicialmente, em achar um lugar capaz de assegurar o equilíbrio precário entre quem olha e quem é olhado. Essa busca de um ponto de vista ou de uma posição do olhar aceitável frente ao outro se traduz, notadamente, pelo recurso do olhar câmera. O olhar câmera, frequentemente associado a uma fixação sobre a imagem, aparece como solução para render o seu olhar ao outro, cuja imagem captamos. E render seu olhar ao outro é, por sua vez, aceitar ser olhado - ao menos, correr o risco disso. Assim, o viajante integra aquele que o vê ao que ele vê: "pois os viajantes de imagens são vistos por imagens maiores que eles”. A sequência a respeito da televisão japonesa fornece um exemplo, cujo comentário reforça 
isso: "Quanto mais vemos a televisão japonesa, mais temos a sensação de sermos vistos por ela” (MARKER, 1993, p. 82 e p. 85).

No primeiro ato, vemos a igualdade do olhar se estabelecer e, no final, assinala-se a realização: "É nos mercados de Bissau e de Cabo Verde que eu reencontrei a legalidade do olhar e esta sequência de figuras tão próximas do ritual da sedução: eu a vejo - ela me viu — , ela sabe que eu a vejo - , ela me oferece seu olhar, mas justo a um ângulo em que é ainda possível fazer como se não estivesse direcionado a mim - e, para terminar, o verdadeiro olhar, diretamente..." (MARKER, 1993, p. 82 e p. 85). A igualdade do olhar é o primeiro contrato entre o viajante e aquele que ele filma. A atenção dada igualmente a todas as coisas, sobretudo as menores, as mais comuns, as mais banais ou aquelas que são ordinariamente negligenciadas, e a maior reciprocidade possível entre quem filma e quem é filmado são as condições de abordagem da alteridade. Mais uma vez coloca-se a ideia de que o que vemos deve também ser visto; ele constata que aquele que o vê é indecifrável: imerso em uma paisagem desconhecida, bombardeada com imagens que ele não compreende, o viajante ainda não encontrou acesso a "imagem do outro".

Pouco a pouco, ele vai começar a procurar as soluções. Ele é curioso, ele quer compreender. Surge, então, uma nova estratégia, que consiste em relatar suas impressões e suas percepções, suas imagens, a outras imagens menos subjetivas, que não são somente suas próprias imagens, imagens que existiam antes dele. $\mathrm{O}$ viajante se move em direção à dupla dimensão da lenda e da história. A segunda e a terceira parte são todas as viagens ao longo da história japonesa e a história da Guiné. Além disso, para usar outras imagens além das próprias, é preciso também, de forma mais metafórica, pegar emprestado imagens de outros cineastas; a terceira parte é quase que inteiramente constituída de tais imagens emprestadas.

A estratégia do viajante tem a forma de uma comparação entre o que ele vê e olha e o que foi visto anteriormente por outro e transmitido a ele. Esse modo de observação tem como objetivo localizar no presente da observação os traços de um passado legendário ou histórico. Todas as tentativas de vincular o presente 
ao passado (para lembrar o olhar do viajante àquele que foi visto anteriormente por outros) serão falhas - sem deixar de formar configurações temporais originais... O aeroporto de Narita oferece a imagem de um presente ou de um passado perpétuo, de um tempo caracterizado pela ausência de mudança. Os diferentes documentos sobre o movimento revolucionário da Guiné mostram um tempo que se repete incessantemente. $\mathrm{O}$ presente anula um passado esquecido, pois um futuro iminente já está pronto para recomeçar. Em Okinawa, nesse lugar onde ocorreu o massacre, resta somente uma loja de suvenires que vende isqueiros em forma de granada: um presente puro, preso entre dois "nada”, radicalmente rompido com o passado (inacessível e quase invisível) e privado de futuro (“...Noro continua a dialogar com os deuses. Depois dela, o diálogo acabará”; MARKER, 1993, p. 93). As imagens históricas, os mitos e as lendas podem responder a esse desejo de compreensão do outro, a essa vontade de saber? Decifrar o indecifrável: história, memória, duas impossibilidades. Nenhum passado jamais explicará o presente: o que os outros viram antes de mim não pode me ajudar a ver e a compreender o que eu vejo.

Ao mesmo tempo, outras imagens se apresentam ao viajante; imagens que pouco a pouco se insinuam para ele. Antes do fim da segunda parte, ele diz: "Cada vez mais meus sonhos se apropriam da decoração das grandes lojas de Tóquio, das galerias subterrâneas que prolongam e duplicam a cidade. Um rosto aparece, desaparece, um traço se encontra, se perde, todo o folclore do sonho está tão bem situado que, no dia seguinte, acordado, eu percebo que eu continuo a procurar no labirinto de subsolos a presença roubada na noite anterior. Eu começo a me perguntar se os sonhos são meus ou se eles fazem parte de um conjunto, de um gigantesco sonho coletivo no qual a cidade inteira seria a projeção" (MARKER, 1993, p. 87). O rosto que aparece e desaparece, a busca de uma presença onírica no subsolo, o sentimento de um sonho roubado do sonhador: percebe-se o quanto Sans soleil faz alusão a La jetée.

Nota-se que nesse momento do filme um Japão singular emerge e começa a se revelar ao viajante através das imagens oníricas - o sonho sendo, como se sabe, um dos lugares 
privilegiados do imaginário. O corpo do viajante, no lugar mesmo da sua maior intimidade, deixa aflorar o rastro de uma impregnação lenta e, por uma transfusão espantosa, esse rastro é lançado para fora dele; em um movimento de ida e volta, o Japão (alguma coisa do Japão) ocupa insidiosamente os sonhos do viajante, e ele mesmo enxerta no rosto impassível de um japonês adormecido fantasmas e sonhos absolutamente violentos (para violentar o aspecto pacífico desses rostos).

As imagens oníricas formam uma alternativa às imagens históricas e legendárias; elas são, de alguma forma, colocadas em concorrência. A questão é saber por quais meios - qual postura, qual imagem (ou quais imagens) - o viajante conseguirá apreender o Japão, ou melhor, conseguirá construir alguma coisa que, para ele, será o Japão. Além dessas imagens oníricas, o imaginário tornase instrumento de conhecimento, a única possibilidade para que a palavra "Japão" venha a fazer sentido (que o conhecimento seja uma armadilha, que o sentido seja ilusório, eu não julgo). Novamente, Le dépays teria aberto o caminho, afirma Marker (1982) no início do livro: "Inventar o Japão é um modo de conhecê-lo como um outro qualquer. Tendo superado o senso comum de fazer oposição ao senso comum, matematicamente as chances são as mesmas para todos". A última parte do filme mostra que o viajante é, doravante, capaz de associar sua imagem ao conjunto.

Última etapa dessa abordagem do outro: o momento em que o sentimento de incompreensão frente à alteridade desaparece. Agora, o viajante pode apreender as imagens do outro, que não são mais terrivelmente indecifráveis, e ele é capaz de associá-las às suas próprias imagens. Ao fazer isso, ele se modifica e torna-se o outro. A relação com o outro se constituiu, e a compreensão do outro se transforma em uma identificação com o outro: "Quando a primavera chegou, quando cada corvo aumentava seus gritos para anunciála, eu pegava o trem em direção a Yamanote Line e eu descia na estação de Tóquio, vizinha do correio central. Mesmo quando a estrada estava vazia, eu parava no sinal vermelho, à japonesa, com o objetivo de deixar o lugar para os espíritos dos carros quebrados. Mesmo sem esperar nenhuma carta, eu parava na frente do correio, 
6. O termo em francês utilizado por Marker é dépaysement. pois é preciso honrar os espíritos das cartas rasgadas, e na frente do guichê do correio aéreo, para saudar os espíritos das cartas não enviadas. Eu media a insuportável vaidade do Ocidente, que nunca parou de privilegiar o ser sobre o não ser, o dito sobre o não dito" (MARKER, 1993, p. 96). Novamente, o paralelo com Le dépays se impõe como um eco a Sans soleil: "Tantas são as coisas do meu país, meu país imaginado, meu país que eu inventei totalmente, meu país que me deixa sem país a ponto de ser eu mesmo apenas nessa desorientação ${ }^{6}$. Meu Dépays" (MARKER, 1982).

O imaginário em Sans soleil é ao mesmo tempo um espaço em que o indivíduo - desdobrado - pode tornar-se interlocutor, um instrumento de conexão entre zonas heterogêneas e um movimento que unifica os contornos da experiência da alteridade. Sobre o imaginário, Mikel Dufrenne (1976, p. 118) escreve que ele une o desejo, a percepção e a linguagem: "Imaginar é talvez pertencer a si mesmo, a seus desejos, estar no mundo, capturar a imagem através da percepção, ser a linguagem; quer dizer, apreender a imagem a partir dos signos que a suscitam e a fixam". Compreendemos que pensar o imaginário em sua dimensão ilusória talvez oculte uma parte de seu trabalho. E, se um filme pode dar conta de tal experiência, de tal processo, compreende-se também que dissociar radicalmente imagens psíquicas de imagens objetos "afeta nossa compreensão uns dos outros" (TISSERON, 1995, p. 13). 


\section{Referências}

AUMONT, J. L'image. Paris: Nathan, 1990.

CHEMAMA, R. La psychanalyse. Paris: Larousse, 1993.

DIDI-HUBERMAN, G. Ce que nous voyons, ce qui nous regarde. Paris: Minuit, 1992.

DUFRENNE, M. "L'Imaginaire”. In: DUFRENNE, M. Esthétique et philosophie, tome 2. Paris: Klincksieck 1976.

GAUTHIER, G. "Chris Marker, cinéaste, téléaste, vidéaste, photographe, écrivain, bricoleur e philosophe”. Bref, n. 6, sept-oct 1990.

KAUFMANN, P. “ Imaginaire et imagination”. In: Encyclopédie Universalis, v. 8, p. 733-738, [s.d.].

KRAUSS, R. "Marcel Duchamp ou le champ imaginaire”. Le Photographique, Paris, Macula, 1990.

LACAN, J. "Le stade du miroir comme fondateur de la fonction du Je, telle qu'elle nous est révélée, dans l'expérience psychanalytique”. In: LACAN, J. Écrits I. Paris: Seuil, 1966.

MARKER, C. Giraudoux. Paris: Seuil, 1952. (Col. Écrivains de Toujours).

Le dépays. Paris: Herscher, 1982. Não paginado.

"Sans soleil" (commentaire). Trafic, n. 6, printemps 1993.

MORIN, E. Le cinéma ou l'homme imaginaire. Paris, Minuit, 1956.

TISSERON, S. Psychanalyse de l'mage: de l'imago aux images vituelles. Paris, Dunod, 1995. 